\section{Small beer, no skittles}

\section{The British research system needs to spend} more on research grants, less on machines.

UNWITTINGLY, the British Science and Engineering Research Council (SERC) has given a telling explanation of why the United Kingdom is considering withdrawal from the European highenergy physics laboratory, CERN, at Geneva. The council's science board, the chief source of research grants for British academics whose interests are not bound up with space, astronomy and high-energy physics, last week published a statement of what it calls its strategy for "core science" - what is left when the great machine-created baronies have been catered for (see Nature 309, 297; 1984).

The results are shocking. The board spends just over $£ 70$ million a year, which is divided into three roughly equal parts, one of which goes to keep the bodies and souls of graduate students and doctoral fellows in some loose correspondence, another on the running of central facilities (such as synchrotron and laser sources) and a third, roughly $£ 25$ million a year, on research grants to working scientists in all disciplines. Having proudly calculated that 12,000 people are dependent on it for research money, it omits the simple arithmetical calculation that there is less than $£ 2,000$ a year for each person on its books.

Lopsidedness also leaps out from this eight-page glossy production. University research in physics, for example, costs the board between $£ 5$ and $£ 6$ million a year. This is hardly the kind of cash flow on which a strategy could be founded. The board says that it is having to refuse nearly a third of grant applications that deserve to succeed. Maybe it should be worrying instead that, with such tiny sums of money at its disposal, it is not much more seriously overwhelmed.

\section{Balkanization}

To be fair to all concerned, these sums are not the whole of what the British research councils spend on the support of academic research. The specialized spending boards into which SERC is balkanized also make grants to academics but, of necessity, the successful applicants there are almost always those whose projects dovetail neatly with the planned use of some machine, observatory, Earth satellite or the like. Other research councils chip in as well; the Medical Research Council spends more on academic biological research than does the science board by a factor of two; the Agricultural and Food Research Council, more deeply committed to its own institutes, also helps, as does even the Natural Environment Research Council. The result, however, is a conspicuous lopsidedness. Why are physics and chemistry research, core sciences if there are any, supported on such a miserly scale?

The usual answer is that that is how the pattern of spending has developed, and that the supply of research grants cannot be too different from the pattern of demand, because the mechanism is self-correcting. This complacent argument overlooks the simple truth that if you starve a field of funds, and spend the best part of a decade telling academic scientists that they would be better employed in other fields, in information technology or engineering for example, they will eventually go elsewhere, intellectually or geographically.

\section{Core science}

In Britain, the problems of core science have been multiplied by the perverse pursuit of over-rational stratagems for economizing in resources. High-powered lasers are in fashion? Then the managers of the research enterprise quickly calculate that they could not provide every likely group with up-to-date equipment so let there be a single central facility that everybody can use, well designed (and slowly built). This is probably the most effective device yet discovered for turning honest scientists into committeepeople, skilled above all at winning allocations of time at facilities which are always more elaborate than would have been necessary for a single purpose - and whose lifetime is assured for years and even decades to come. So it turns out that with the passage of time, young men who embark with enthusiasm on working as attendants of the big machines (even the small big machines) discover that they are no longer practitioners of the craft that attracted them but rather managers, negotiators, sometimes even diplomats.

Nobody suggests that it would be possible to turn back the clock so far that the practice of science in the physical sciences would be exclusively modelled on what happened in the nineteenth century. It is however likely, with the present distribution of resources in Britain between machine science and small-scale science, that the pendulum has swung far too far towards the machines. There is no evidence that people dislike working with the large machines but that is not the point. What matters is that the way in which the machines claim people's allegiance for years on end ensures that the community of scientists in a country as small as Britain is less flexible than it might be, less able to seize new opportunities.

The science board seems at least to have understood the way in which changes should be brought about. Its strategy document says that it needs more money and that if it had more money it would give first priority to research grants and the last to the strengthening of machine facilities. But how long does the science board think it would take to effect a noticeable change in the pattern of scientific research if on the one hand it is going to adjust its distribution of resources only when the total is increasing and if at the same time it follows its own prescription of giving particular attention to projects which have industrial potential? One of the constantly repeated mistakes in the management of British civil science in the past few decades is that with each new economic crisis, the research councils whose responsibility is to ensure the health of basic science have felt it necessary to demonstrate that they too have to put their shoulders to the wheel, helping with chemical engineering one decade, information technology the next.

Mercifully, there are signs that even this preoccupation may soon be modified. In the past six months, SERC, recognizing the dangers of over-dependence on machines, has tried to create a set of circumstances in which the two big spenders among its committees, the astronomy, space and radio board and the nuclear physics board, would be merged, presumably so that they would then take a more sceptical view of what their enforced partners were supporting. It is a well-known failing of even the best intentioned systems for distributing money for research that peer review is harder to trust as the scale of projects grows. Unfortunately, SERC has for the time being defeated its chairman's plan to bring about this marriage. He (or his successor) should not however let the matter rest there. The case for having rational means of distinguishing between the merits of different proposals is too strong to be forgotten.

The grant-making establishment needs also to safeguard itself against repetition of the mistakes that have recently caused such trouble. Logical though it is to think of serving many users and saving money at the same time by the provision of central facilities which all experimenters can use, the system is also a recipe for diseconomy. Would it not be better, as in the United States, that if a person thinks it would be valuable to have a machine for accelerating particles, or producing intense monochromatic beams of light, or even perhaps a machine for producing neutrinos, he should not be prevented from applying for the money he needs by the argument that the project is too big for one man to handle? Of course that is literally true. But elsewhere, in the United States particularly, there is now a long record of successful exploitation of the principle that the most enthusiastic user of a novel kind of machine is likely to be the man who gave the reasons why it should be built. And then, of course, if two people have the same idea for a new machine at the same time, there can be a competition. Either way, the enterprise is likely to be carried out more economically than would otherwise be possible, fewer people will acquire a vested interest in its perpetual continuation and, indeed, there would be many occasions when designers of new experiments on a large scale were treading on their own heels, anxious to get rid of what they had been anxious to build only a little while earlier. 